\title{
LA VIOLENCIA TRANSGENERACIONAL HACIA LA MUJER EN CUENTOS DE JOYCE Y PARDO BAZÁN
}

\author{
A VIOLÊNCIA TRANSGERACIONAL CONTRA A MULHER EM \\ CONTOS DE JOYCE E PARDO BAZÁN
}

\section{TRANSGERATIONAL VIOLENCE AGAINST WOMEN IN JOYCE AND PARDO BAZÁN SHORT STORIES}

\author{
Bárbara Loureiro Andreta ${ }^{1}$ \\ [http://orcid.org/0000-0001-5657-2030] \\ Luciana Ferrari Montemezzo ${ }^{2}$ \\ [http://orcid.org/0000-0002-4632-5543] \\ DOI: 10.30612/raido.v14i35.11070
}

\begin{abstract}
RESUMEN: Este trabajo tiene el objetivo de comparar los cuentos "Eveline" (1904), de James Joyce y "Las medias rojas" (1914), escrito por Emilia Pardo Bazán. En "Eveline", la protagonista Eveline desea emigrar de Irlanda para vivir con su novio. En "Las medias rojas", Ildara desea salir de Galicia. En ambos casos, las emigraciones no se concretan: en el primero de ellos, Eveline desiste de partir, inmovilizándose en el puerto, ante la partida de su amado. En el segundo, el padre de la protagonista le pega una paliza, para que no emigre. En ambos cuentos se destaca la violencia hacia las mujeres: en "Eveline", esta violencia es más bien psicológica y económica, mientras que en "Las medias rojas", dicha violencia, además de psicológica y económica, es también física. En ese sentido, este trabajo plantea analizar los cuentos teniendo en cuenta la violencia de género a que se les sujetan las protagonistas, considerando todavía los patrones familiares de violencia. Para ello, se propone usar el concepto psicoanalítico de 'trasgeneracionalidad'.
\end{abstract}

Palabras-clave: "Eveline”, "Las medias rojas", James Joyce, Emilia Pardo Bazán, violencia de género.

RESUMO: Este trabalho tem como objetivo comparar os contos "Eveline" (1904), de James Joyce e "Las medias rojas" (1914), escrito por Emilia Pardo Bazán. Em "Eveline", a protagonista Eveline deseja emigrar da Irlanda para viver com seu namorado. Em "Las medias rojas", Ildara deseja sair da Galícia. Em ambos os casos, as emigraçóes năo se concretizam: no primeiro, Eveline desiste de partir, ficando imóvel no porto

\footnotetext{
1 Doutoranda em Letras - Estudos Literários pela Universidade Federal de Santa Maria (UFSM).

2 Doutora em Teoria e História Literária pela Universidade Estadual de Campinas (UNICAMP). Professora no Programa de Pós-graduaçăo em Letras da Universidade Federal de Santa Maria (UFSM).
} 
diante da partida de seu amado. No segundo caso, o pai da protagonista a agride, para que a filha nâo parta. Em ambos os contos, se destaca a violência contra a mulher: em "Eveline", esta violência é mais psicológica e econômica, enquanto que em "Las medias rojas", tal violência, além de psicológica e econômica, é também física. Nesse sentido, este trabalho pretende analisar os contos, considerando a violência de gênero a que as protagonistas estâo submetidas, considerando padróes familiares de violência. Para isso, propóe-se utilizar o conceito psicanalítico de 'trangeracionalidade'.

Palavras-chave: “Eveline"; "Las medias rojas"; James Joyce; Emilia Pardo Bazán; violência de gênero.

ABSTRACT: This work aims at comparing the short stories "Eveline" (1904) by James Joyce and "Las medias rojas" (1914) written by Emilia Pardo Bazán. In "Eveline", the protagonist Eveline wants to emigrate from Ireland to live with her boyfriend. In "Las medias rojas", Ildara wants to leave Galicia. In both cases, the emigration wishes do not become real: in the first, Eveline gives up leaving her country. She was motionless at the port when her beloved left. In the second one, the protagonist's father assaults her to force her to stay. In both short stories it is highlighted the violence against women: in "Eveline", such violence is more a psychological and economic one while in "Las medias rojas", besides being psychological and economic, the violence is also physical. In this sense, this work aims at analyzing the short stories taking into consideration the gender violence that the protagonists suffer regarding family patterns of violence. To do so, it is applied the 'transangerationality' psychoanalytic concept for the analyses.

Keywords: "Eveline", "Las medias rojas", James Joyce, Emilia Pardo Bazán, gender violence.

\section{LOS AUTORES Y SUS OBRAS}

Emilia Pardo Bazán nació en La Coruña, España, en 16 de septiembre de 1851. La escritora es autora de novelas como Un viaje de novios (1881), La Tribuna (1882) y Los pazos de Ulloa (1886), además de varios cuentos, que se dividen, de acuerdo con su temática, en Cuentos de amor, Cuentos de la patria, Cuentos de la tierra, Cuentos de Marineda, Cuentos de Navidad y Reyes, Cuentos del terruño, Cuentos dramáticos, Cuentos nuevos, Cuentos sacroprofanos y Cuentos trágicos. James Joyce, por su parte, nació en Rathgar, en las afueras de Dublín, Irlanda, en 02 de febrero de 1882. Entre sus obras más conocidas están Exiliados (1918), ${ }^{3}$ Ulises (1922) y el libro de cuentos Dublineses, publicado en 1914.

3 De acuerdo con Hélio de Mello Filho (2001, p. 245), Joyce ha escrito la obra Exiliados entre los años 191415 y fue publicada en 1918, por la editorial Gran Richards, en Londres y por la The Vicking Press, en Nueva York. Además, Mello Filho (2001, p. 245) destaca que esta es la primera y única obra dramática publicada por James Joyce, teniendo en cuenta que otra obra suya, A Brillant Career (1901) la ha destruido el mismo autor. 
El cuento "Las medias rojas", de Emilia Pardo Bazán (2001), ${ }^{4}$ publicado por primera vez en 1914, integra los Cuentos de la Tierra y narra la historia de la joven Ildara, una chica originaria de Galicia, que desea emigrar. Pero su padre le impide realizar el deseo de embarcar en el buque que la llevaría hacia su sueño: la agrede con extremada violencia que acaba por quitarle una muela y pierda la visión de uno de los ojos, a causa de un desprendimiento de la retina. El cuento "Eveline", de James Joyce, ha sido publicado en un periódico irlandés en 1904 (IGLESIAS, 2011 - 2012, p. 146) y, en 1914, publicado en el libro de cuentos Dublineses ${ }^{5}$. En "Eveline", se narra la historia de la protagonista homónima, que decide partir de Irlanda con su novio, un joven marinero, con destino a Buenos Aires. Su partida, tal como la de Ildara no se concreta, no a causa de violencia física explícita como le ha pasado a Ildara, sino por una especie de parálisis que le impide a la joven irlandesa de embarcar, inmovilizándola en el puerto, mientras observa la partida del buque.

Christina Iglesias (2011 - 2012, p. 146) defiende que las similitudes entre los dos cuentos se relacionan mucho a las circunstancias en que se encuentran Galicia e Irlanda en el periodo, mitad del siglo XIX. En esa época, las tasas de emigración eran muy altas tanto en Galicia como en Irlanda: apenas entre 1911 y 1913, el 29,62\% de los espańoles que dejaron su país eran originarios da Galicia, destacándose como el grupo más significativo de los inmigrantes españoles que llegaban a Buenos Aires (IGLESIAS, 2011 - 2012, p. 146). En ese sentido, ambos cuentos representan un reflejo de sus habitantes en el siglo XIX.

Más allá del tema de la migración, los cuentos reflejan y provocan reflexiones sobre las violencias que se practican en el ambiente doméstico y familiar. Nuestro trabajo tiene el objetivo de analizar las transmisiones transgeneracionales $\mathrm{y}$, especialmente, los comportamientos violentos que se repiten a lo largo de las generaciones en "Las medias rojas" y en "Eveline".

\section{EL PESO DE LA TRANSMISIÓN ENTRE GENERACIONES}

El concepto de identificación ha sufrido algunas alteraciones a lo largo de la obra freudiana. Según pone de relieve Nussbaum (2009, p. 154), inicialmente Freud pensaba que la herencia podría ser transmitida de modo filogenético. A partir de ello, el pensador austríaco ha explicado, por ejemplo, los conceptos como la represión primaria, en Tres ensayos de la teoría sexual (1905/1996). De la misma manera, ese fue el modelo explicativo utilizado para la prohibición del parricidio en Toten y Tabú (1913/1996). A partir de la publicación de Duelo y Melancolía (1917/1996), Psicología de las masas y análisis del Yo (1923/1996), y especialmente El yo y el ello (1923/1996), Freud pasa a comprender el 'yo' como la sede de las identificaciones, como la instancia que se forma a partir de las identificaciones, del conflicto edípico y del 'superyó', entonces, heredero del Complejo de Edipo. Bajo esa nueva perspectiva, el sujeto del inconsciente no es sólo un sujeto de pulsión, sino más bien un sujeto de herencia, que tiene su subjetividad

4 Publicado por la Biblioteca Virtual Miguel de Cervantes, en 2001, a partir de las Obras Completas v. II, $4^{\text {a }}$ ed., Madrid, Aguilar, 1964, pp. 1474-1562.

5 Iglesias (2011 - 2012, p. 146) destaca que se ha traducido "Eveline" al español, por primera vez, en 1928. 
instituida por identificaciones adquiridas en el seno de una matriz familiar que tiene la función de asignarle lugares, plantar ideas, prescripciones y prefigurar conflictos (NUSSBAUM, 2009, pp. 154-155).

Ana Rosa Chait Trachtenberg (2007, pp. 342-343) señala que transmitir es pasar un objeto de identificación, un pensamiento, una historia o afectos de una persona a otra, de un grupo a otro, o de una generación a la otra. Dicha autora destaca que hay dos modalidades básicas de transmisión psíquica, la transmisión intergeneracional y la transmisión transgeneracional. La transmisión intergeneracional acontece entre las generaciones, habiendo una distancia, un espacio entre lo que se puede llamar "transmisor" y "receptor", de forma a preservar las subjetividades. La transmisión transgeneracional, por su parte, es invasiva y sobreviene a través de los sujetos y generaciones.

En las transmisiones intergeneracionales, el sujeto es, además de beneficiario, heredero, servidor forzado, un adquiriente de lo que se le transmite. En ese sentido, se trata de un trabajo psíquico de elaboración en lo que atañe al sujeto y a su grupo, en la manera de favorecer transformaciones y conducir las diferenciaciones, hacia lo que es heredado, permitiendo que cada generación se sitúe ante las otras, percibiendo y respetando las diferencias entre sí (TRACHTENBERG, 2007, p. 344).

La transmisión transgeneracional es una transmisión psíquica entre generaciones que, desde el punto de vista de la naturaleza y del eslabón entre las generaciones, se ha hecho defectuosa o, en cierta medida, interrumpida. En ese tipo de transmisión psíquica, las historias de los personajes familiares están colapsadas, coladas unas a las otras, se encuentran bajo el predominio de la repetición y del narcisismo. En ambas generaciones, tanto en la "transmisora" cuanto en la "receptora", hay lo impensable, lo indecible, lo negativo, el proceso de mantener guardados los secretos, los pasados silenciados y las historias vacías (TRACHTENBERG, 2007, p. 345-349). Según Trachtenberg (2007, pp. 345-349), la nueva generación se presenta como una heredera compulsoria y "continente de lo negativo", receptora de una transmisión defectuosa y que, por verse dominada por la dependencia y por el apego a los padres, bien como por la necesidad de ocupar el lugar que se les determina, tratará de todas las maneras, libertarse de esa carga siempre que haya algún tipo de predominio de la pulsión de vida.

\section{1. "las medias rojas"}

En el cuento "Las medias rojas", la protagonista es Ildara, una muchacha que acaba de cumplir la mayoría de edad y vive con su padre, un señor viudo. El relato tiene su ápice cuando Clodio, padre de Ildara se percata de que la muchacha lleva medias rojas:

[...] Como Ildara se inclinase para soplar y activar la llama, observó el viejo cosa más insólita: algo de color vivo, que emergía de las remendadas y encharcadas sayas de la moza... Una pierna robusta, aprisionada en una media roja, de algodón...

¡Ey! ¡Ildara!

-¡Señor padre!

-¿Qué novidá es esa?

-¿Cuál novidá?

-¿Ahora me gastas medias, como la hirmán del abade?

Incorporóse la muchacha, y la llama, que empezaba a alzarse, dorada, lamedora de 
la negra panza del pote, alumbró su cara redonda, bonita, de facciones pequeñas, de boca apetecible, de pupilas claras, golosas de vivir (PARDO BAZÁN, 2001, [s.p.]).

La información de que Ildara llevaba las faldas remendadas aparece, aquí, como una indicación de las condiciones económicas de la familia: las mismas dificultades financieras por las cuales pasaba grande parte da población gallega, a mitad del siglo XIX, provocando la inmigración a América. El incómodo del padre para con las medias rojas se relacionaba a lo económico, no sólo porque Ildara habría malgastado el dinero al comprar las medias, sino también por el sentido que el padre le atribuye a las medias rojas, como estando relacionadas a la manera de vestirse de muchachas de mala reputación.

En ese sentido, Iglesias (2011-2012, p. 146) señala que en ambos cuentos es posible identificar la amenaza implícita de prostitución forzada en tierras extranjeras. A pesar de ello, tanto Ildara como Eveline desean escapar - tal vez sin darse cuenta de dicha amenaza - anhelando conseguir independencia y estabilidad económica.

El estilo de Ildara, asociado a una dudosa reputación aparece desde el inicio del cuento: "Ildara soltó el peso en tierra y se atusó el cabello, peinado a la moda "de las señoritas" [...]" (PARDO BAZÁN, 2001, [s.p.]). El padre le reprocha a Ildara su comportamiento, que la compara a su madre: "-Ya te cansaste de andar descalza de pie y pierna, como las mujeres de bien, ¿eh, condenada? ¿Llevó medias alguna vez tu madre? ¿Peinóse como tú, que siempre estás dale que tienes con el cacho de espejo? Toma para que te acuerdes..." (PARDO BAZÁN, 2001, [s.p.]). Se observa que, el padre comprende la vanidad de la hija como un comportamiento inadecuado y reprensible. Como forma de censurarla, Clodio le recuerda a la hija que su madre no llevaba medias y no se peinaba como Ildara. Tal observación parece estar a servicio de una exigencia para que Ildara sea una mujer igual a su madre, una "mujer de bien". Con tales palabras, el padre no apenas exige que la muchacha repita el modelo de mujer que ha sido su madre, sino que sostiene aquél modelo de mujer como el único a seguirse. Con ello, no permite que la hija construya, en su propia historia, su mismo modelo, sin la necesidad de repetir el modelo materno.

Tras esa discusión, Clodio le confronta a Ildara:

Y con el cerrado puño hirió primero la cabeza, luego, el rostro, apartando las medrosas manecitas, de forma no alterada aún por el trabajo, con que se escudaba Ildara, trémula. El cachete más violento cayó sobre un ojo, y la rapaza vio como un cielo estrellado, miles de puntos brillantes envueltos en una radiación de intensos coloridos sobre un negro terciopeloso. Luego, el labrador aporreó la nariz, los carrillos. Fue un instante de furor, en que sin escrúpulo la hubiese matado, antes verla marchar, dejándole a él sólo, viudo, casi imposibilitado de cultivar la tierra que llevaba en arriendo, que fecundó con sudores tantos años, a la cual profesaba un cariño maquinal, absurdo. [...]

Salió fuera, silenciosa, y en el regato próximo se lavó la sangre. Un diente bonito, juvenil, le quedó en la mano. Del ojo lastimado, no veía (PARDO BAZÁN, 2001, [s.p.]).

Este fragmento del cuento destaca la extremada violencia tanto física cuanto psicológica hacia Ildara, señalando patrones familiares de comportamiento violento que se repiten. La violencia física, cruel y explícita, que impide a la joven seguir su deseo y partir para a América, asumiendo el curso de su misma vida, es un comportamiento 
familiar que se repite: una prima suya ya había sufrido semejante violencia por parte de su madre: "Era siempre su temor de mociña guapa y requebrada, que el padre la mancase, como le había sucedido a Mariola, su prima, señalada por su propia madre en la frente con el aro de la criba, que le desgarró los tejidos" (PARDO BAZÁN, 2001, [s.p.]). El hecho de que Ildara le temiera a su padre y que algún día le pasara a ella lo que le había pasado a la prima lleva el lector a suponer que Clodio ya había presentado comportamiento violento para con su hija y también permite que se piense en un patrón de comportamiento extremadamente violento y repetitivo por parte de las generaciones anteriores para con las generaciones más jóvenes.

Además de ello, es importante poner de relieve que la violencia física que ejerce Clodio estaba directamente relaciona a dos situaciones de violencia psicológica, una de ellas lo dicho y lo no dicha. La situación dicha es verbalizada por Clodio y considerada el motivo por el cual el padre le pega una paliza a Ildara: las medias rojas, asociadas a un comportamiento que el padre recrimina en una "mujer de bien". También le parece reprochable al padre que su hija haya malgastado el dinero en las medias. El tema que se considera aquí como no dicha, pues no se le revela al lector explícitamente - a través del habla de los personajes, por ejemplo -, sino por la voz narrativa. En ese sentido, al no verbalizarse, no se constituye una cuestión familiar, lo que la hace más fuerte y aún más significa: el hecho que, para el padre, era preferible matar a su hija que verla partir y dejarlo solo, ya que emigrar no formaba parte de sus planes, a causa del amor que le tenía a la tierra que cultivaba.

El cuento no ofrece elementos que señalen cómo y dónde ha muerto la madre de Ildara, pero ante la inmovilidad de su padre y de su concepción de que la esposa es una "buena mujer", el lector puede suponer que la madre de Ildara ha fallecido en Galicia, al lado de su marido. Es importante mencionar aquí a lo que señala Trachtenberg (2007, p. 345-349), cuando se refiere a las transmisiones transgeneracionales: las historias de vida se "pegan" las unas a las otras, de forma que, para la generación más joven, la única posibilidad es repetir la historia de las generaciones anteriores, estableciéndose como receptora de una transmisión problemática.

En ese sentido, una vez más Clodio exige que Ildara repita la historia familiar: la de su madre, por medio de la inversión de la línea de generaciones, al exigirle a la hija que permanezca a su lado y no lo deje solo. Actuando de tal manera, Ildara pasaría a jugar, en tesis, el rol designado a la compañera; y se mantendría en un lugar importante para su padre, echando mano de construir su misma historia y de lo que estaba dispuesta a construir para su vida. Además, cuando la voz narrativa revela que el padre hubiera preferido matar a la hija a verla partir, se puede pensar que tal vez, para Clodio, el miedo a la soledad era menor que el miedo que la familia no creara raíces en un lugar importante y significativo para él. Según tal perspectiva, era preferible que la hija estuviera muerta en Galicia que viva en América. Teniendo en cuenta su cariño maquinal, absurdo por la tierra, se puede pensar en un deseo suyo que la hija fuera una extensión narcísica suya y, por lo tanto, siguiera en aquel espacio tan significativo para él.

Siendo así, cuando el padre le impide viajar y seguir sus proyectos de vida, Ildara se siente condenada, por medio de violencia física, psicológica, de dichos y de no dichos a repetir la historia de sus padres. Trachtenberg (2007, p. 345-349) destaca que la generación más joven, al verse dominada por el apego a los padres y por la necesidad 
de ocupar el lugar que ellos le han asignado, busca, de todas formas, libertarse de esa carga siempre que exista un predominio de la pulsión de vida. En el caso de Ildara, es posible comprender en su intento de partir, la búsqueda por libertarse, no solo de las imposiciones de su padre, sino también del peso que conlleva la repetición de las historias de vida de las generaciones anteriores. Sin embargo, debido a la violencia paterna, Ildara ha sido imposibilitada de vivir su propia historia. Así, está condenada a vivir una no-historia, una historia que no era la suya, sino la de sus progenitores.

\section{2. "Eveline"}

"Eveline" narra la historia de la protagonista homónima que, enamorada de Frank, su novio, decide partir con él hacia Buenos Aires. A lo largo del cuento, el lector se va enterando de la historia personal y familiar de la joven: la madre había fallecido, así como uno de sus hermanos. Otro hermano se va de viaje durante la gran parte del tiempo, a causa de su trabajo como decorador de Iglesias. Eveline, por su parte, vivía con el padre, que no se volvió a casar. El viaje a Buenos Aires, sin embargo, no se concreta, ya que Eveline se queda paralizada en el puerto, viendo la partida de su amado.

De acuerdo con Daniel Puglia (2006, p. 90), de una manera general, los personajes de Dublineses se encuentran atrapados en contextos de opresión. Dicha realidad, por otro lado, parece permitir alteraciones por medio del silencio, de la picardía o del exilio. Además, en lo que atañe a los personajes femeninos, Puglia (2006, p. 90) destaca lo propuesto por James Fairhall (1993, p. 250 apud Puglia, 2006, p. 90): dichos personajes tendrían propensión a representar concordancia con el orden establecido en una Dublin colonial y paralizada. En ese sentido, Puglia (2006, p. 92) pone de relieve que se puede pensar en el malestar y la incomodidad que Eveline experimenta en conjunto con los demás cuentos de Dublineses. Así, representarían un contexto más general y amplio, que afligiría a los dublineses de una determinada clase social. Estos estarían aprisionados a la moral pequeño-burguesa, dominados por la limitación de sus mismas expectativas. De esa manera, Joyce ha representado dichos temas, como una notoria consecuencia del dominio ideológico impuesto por la familia, por la metrópolis británica y por la religión (PUGLIA, 2006, p. 92).

De la misma manera que Ildara, en "Las medias rojas", Eveline tiene una relación difícil con su padre, lo que aumenta su deseo de partir con Frank. A pesar de que no hay indicios de violencia física en "Eveline", la joven irlandesa era amenazada:

\footnotetext{
Pero en su nueva casa, en un país lejano y extraño, no pasaría lo mismo. Luego - ella, Eveline - se casaría. Entonces la gente sí que la respetaría. No iba a dejarse tratar como su madre. Aún ahora, que tenía casi veinte años, a veces se sentía amenazada por la violencia de su padre. Sabía que era eso lo que le daba palpitaciones. Cuando se fueron haciendo mayores él nunca le fue arriba a ella, como le fue arriba a Harry y a Ernst, porque ella era hembra; pero últimamente la amenazaba y le decía lo que le haría si no fuera porque su madre estaba muerta. Y ahora no tenía quien la protegiera [...] (JOYCE, 2007, p. 41).
}

Se puede suponer, a partir del fragmento anteriormente mencionado que Eveline era preterida en relación a sus hermanos no solo por ser mujer, sino porque deseaba no sufrir como su madre, según nos informa el relato. En otro momento del cuento se enfatiza el sufrimiento de la madre de Eveline: 
Mientras rememoraba, la lastimosa imagen de su madre la tocó en lo más vivo de su ser - una vida entera de sacrificio cotidiano para acabar en la locura total. Temblaba al oír de nuevo la voz de su madre diciendo constantemente con insistencia insana:

¡ Derevaum Seraun! ¡Derevaun Seraun!

Se puso en pie bajo un súbito impulso aterrado. ¡Escapar! ¡Tenía que escapar! Frank sería su salvación. Le daría su vida, tal vez su amor. Pero ella ansiaba vivir. ¿Por qué ser desgraciada? Tenía derecho a la felicidad. Frank la levantaría en vilo, la cargaría en sus brazos. Sería su salvación (JOYCE, 2007, pp. 43-44).

Fairhall (1993, p. 65 apud PUGLIA, 2006, pp. 92-93) defiende que hay una unidad en los cuentos de Dublineses, la cual tendría el tema de la parálisis como clave interpretativa, o sea, la lucha de los personajes contra las circunstancias opresoras vivenciadas en Irlanda. En ese sentido, el autor entiende que "Derevaun Seraun! Deveraun Seraun!" suenan como gaélico, pero no lo son. Dicha expresión sigue generando mucho debate hasta hoy entre los estudiosos de la obra de Joyce. Probablemente, la expresión "the end of pleasure is pain" podría considerarse como un equivalente suyo, aunque pese que no hay consenso sobre ello entre los críticos de Joyce. Sin embargo, hay un consenso de que se trata de una variante del gaélico o de un dialecto del oeste de Irlanda. En ese sentido, Fairhall (1993, p. 77 apud PUGLIA, 2006, pp. 92-93) señala que es posible entender el contexto como un idioma luchando dentro de otro. Tal hecho ilustra cuestiones históricas del siglo XIX irlandés, sus transformaciones y la imposición del inglés como idioma oficial. Aún de acuerdo con el investigador, las palabras de la madre estarían relacionadas al testimonio del trauma, habiendo sido aprendidas con progenitores en el momento que la familia tuvo que salir del campo para la ciudad, a causa de problemas económicos. Esas palabras serían, entonces, el reflejo de una historia reprimida por los dublineses (PUGLIA, 2006, p. 93).

En dicho contexto y considerándose lo propuesto por Fairhall (1993), es posible comprender que las palabras de la madre de Eveline se relacionan directamente a la transmisión transgeneracional, puesto que, por tratarse de una historia reprimida, la cual los sujetos remotamente pueden recordar como trauma, está a servicio del olvido, de la no-historia y de la repetición, constituyéndose como una transmisión invasiva, que pasa directamente a través de las generaciones, sin que sea mínimamente elaborada.

No sólo el recuerdo de la enfermedad mental y de la muerte de su madre en Dublín, sino también el anhelo de que su vida y su futuro fueran distintos mueven a Eveline a huir hacia Buenos Aires, donde cree que podrá ser amada y tener una vida de verdad. En ese sentido, para la joven, Frank está asociado a la vida, no solo porque es la persona que le puede quitar del sitio de sufrimiento en donde se encuentra, sino que también representa algo que ella deseaba para sí misma: la posibilidad de emigrar y empezar de nuevo la vida. Por lo tanto, Frank está para la vida como su familia está para la enfermedad y la muerte.

Además de ello, es importante poner de relieve que Eveline había hecho una promesa a su fallecida madre: antes de su muerte, le había prometido hacerse cargo de la casa mientras fuera necesario:

A lo lejos, en la avenida, podía oír un organillo. Conocía la canción. Qué extraño que la oyera precisamente esta noche para recordarle la promesa que hizo a su madre: la promesa de sostener la casa cuanto pudiera (JOYCE, 2007, p. 43). 
Probablemente, el peso de tal promesa, hecha en el lecho de muerte de su madre, era lo que la mantenía a la chica en Dublín y, por ende, la aprisionaba a la historia de su madre, que ella tanto temía repetir.

Se entiende que al mantener la promesa, Eveline acaba asumiendo la obligación en reproducir la historia de su madre. Cuando le pide a la hija que se haga cargo de la casa, la madre la aprisiona a la casa paterna, a Dublín y al comportamiento violento y controlador de su padre. Es posible que ese poder de represión sea más importante que la autoridad paterna, una vez que proviene de una repetición que, al no percibirse, puesto que está reprimida, no puede contestarse, condenando a todos a un eslabón traumático transgeneracional.

En el final del cuento, Eveline desiste de partir y se mantiene paralizada en el puerto ante la partida de Frank:

\begin{abstract}
Se apresuró a pasar la barrera, diciéndole a ella que lo siguiera. Le gritaron que avanzara, pero él seguía llamándola. Se enfrentó a él con cara lívida, pasiva, como un animal indefenso. Sus ojos no tuvieron para él ni un vestigio de amor o de adiós o de reconocimiento (JOYCE, 2007, p. 45).
\end{abstract}

Ante lo expuesto, es posible que se entienda la actitud de Eveline, su parálisis e inercia, como una forma de identificación de la protagonista con su madre muerta. Eveline se ha quedado en el puerto como un animal condenado, condenada por la promesa, por su madre, a repetir la historia, a permanecer en Dublín con su padre violento. Bajo tal óptica, surge la imagen dicotómica de la madre, la misma madre que la protegía, "pero últimamente la amenazaba y le decía lo que le haría si no fuera porque su madre estaba muerta. Y ahora no tenía quien la protegiera [...]" (JOYCE, 2007, p. 41). La madre la había condenado a convivir con el padre violento, asumiendo las funciones de cuidar de la casa, funciones que antes habían sido de la madre. De esa manera, se puede pensar que, al imponerle la promesa a la hija, la madre propicia la inversión de la línea de generaciones, una vez que a la hija se le ha pedido que asumiera funciones que le tocaban, hasta la generación anterior, a la madre. La transmisión transgeneracional se sobrepone a los sujetos, definiendo repeticiones de historias de vida (TRACHTENBERG, 2007, p. 345-349). De esa manera, Eveline no solo repite la historia de su madre, permaneciendo en Dublin y dedicándose a la familia - de acuerdo con lo que le había prometido a la madre en su lecho de muerte. Más que eso: en un momento decisivo de su vida, se identifica con la madre muerta de tal manera que dicha identificación no le permite partir y asumir su propia vida.

\title{
3 CONSIDERACIONES FINALES
}

Se puede concluir que tanto en "Las medias rojas" como en "Eveline" hay repeticiones de comportamientos violentos en el ambiente familiar, tanto en lo que atañe a la violencia en sí misma como también en una 'condenación' a vivir en situaciones violentas. Tanto a Ildara como a Eveline se las ha condenado a repetir las historias de sus familias. Dicha repetición les insertó a las dos chicas en ambientes violentos y vulnerables, en hogares y relaciones violentas. 
En ambos casos, la transmisión transgeneracional está a servicio de la no historia, puesto que condenaba a las jóvenes a vivir y repetir las historias de otros, de sus padres, y no vivir su misma historia. Además, hay que considerarse los acontecimientos traumáticos no elaborados, como las muertes de las madres: en Eveline, la protagonista acaba por identificarse con la historia materna y la repite; Ildara, por su turno, parece estar menos identificada con su madre, pero el duelo mal elaborado de su padre la condena a la repetición y le impide de vivir la vida que ha planificado para sí.

Algunos índices permiten pensar que quizás la única manera de huir de la transmisión transgeneracional y crear una nueva historia pasaría no solo por la salida del lugar de nacimiento y el abandono del hogar, sino también por la prostitución. En ese sentido, desafortunadamente, los dos cuentos seńalan el rol de inferioridad y que se les asignaba a las mujeres a la época de Pardo Bazán y Joyce. 


\section{REFERENCÍAS}

FAIRHALL, J. James Joyce and the Question of History. Cambridge, Cambridge University Press, 1993.

FREUD, S. Três ensaios da teoria da sexualidade. In: . Obras psicológicas completas de Sigmund Freud. v.VII. Rio de Janeiro: Imago, 1996 [1905], pp. 119-231.

FREUD, S. Totem e Tabu. In: Obras psicológicas completas de Sigmund Freud. v. XIII. Rio de Janeiro: Imago, 1996 [1913], pp. 13-161.

. O Ego e o Id. In:__. Obras psicológicas completas de Sigmund Freud. v. XIX. Rio de Janeiro: Imago, 1996 [1923], pp. 15-81.

IGLESIAS, C. "Eveline" and "Las medias rojas": Joyce, Emilia Pardo Bazán, and the Emigration Question. Papers on Joyce. n. 17/18, 2011 - 1012, pp. 145-158.

JOYCE, J. “Eveline”. In: JOYCE, James. Dublinenses. Córdoba: Ediciones del Sur, 2007, pp. 39-45.

MELLO FILHO, H. A peça esquecida de James Joyce. Cadernos de Literatura em Traduçăo (USP). n. 4, 2001, pp. 245-272. Disponible en: http://www.revistas.usp.br/clt/article/ view/49358/53439. (fecha de consulta: 02/01/2019).

NUSSBAUM, S. Identificaciones alienantes y repetición. Una contribución acerca de la transmisión transgeneracional. Psicoanálisis (Asociación Psicoanalítica de Buenos Aires).v. XXXI - n. 01, 2009, p. 153-166.

PARDO BAZÁN, E. "Las medias rojas". In: PARDO BAZÁN, Emilia. Cuentos de la tierra. Alicante: Biblioteca Virtual Miguel de Cervantes, 2001. Disponible en: http://www. cervantesvirtual.com/obra-visor/cuentos-de-la-tierra--0/html/dcb42d82-2dc6-11e2-b417-000475f5bda5_2.html\#I_1_. (fecha de consulta: 18/07/2018).

PUGLIA, D. Revelaçăo e Paralisia em James Joyce. Crop (FFLCH/USP), v. 11, 2006, pp. 89-94.

TRACHTENBERG, A. R. C. A força da transmissăo entre geraçōes e o transgeracional. Psicanálise (Sociedade Brasileira de Psicanálise de Porto Alegre). v. 9, n. 2, 2007, pp. 341-354. 